\title{
Phase III: Implementation and Operation of the Repository
}

\author{
Quarterly Report \\ January 1 - March 31, 1998
}

Work Performed Under Contract No.: DE-FG22-97BC14847

\author{
For \\ U.S. Department of Energy \\ Office of Fossil Energy \\ Federal Energy Technology Center \\ P.O. Box 880 \\ Morgantown, West Virginia 26507-0880
}

By

American Geological Institute

4220 King Street

Alexandria, Virginia 22302-1502 


\section{Disclaimer}

This report was prepared as an account of work sponsored by an agency of the United States Government. Neither the United States Government nor any agency thereof, nor any of their employees, makes any warranty, express or implied, or assumes any legal liability or responsibility for the accuracy, completeness, or usefulness of any information, apparatus, product, or process disclosed, or represents that its use would not infringe privately owned rights. Reference herein to any specific commercial product, process, or service by trade

name, trademark, manufacturer, or otherwise does not necessarily constitute or imply its endorsement, recommendation, or favoring by the United States Government or any agency thereof. The views and opinions of authors expressed herein do not necessarily state or reflect those of the United States Government or any agency thereof. 


\title{
NATIONAL GEOSCIENCE
}

\section{DATA REPOSITORY SYSTEM}

\section{PHASE III: IMPLEMENTATION AND OPERATION OF THE REPOSITORY \\ PROGRESS REPORT DE-FG22-97BC-14847}

\author{
1st Quarter \\ January-March, 1998 \\ Submitted by the \\ AMERICAN GEOLOGICAL INSTITUTE \\ to the
}

Office of Fossil Energy, U.S. Department of Energy

\section{April 1998}

American Geological Institute, 4220 King Street, Alexandria, VA 22302-1502

(703) 379-2480 Fax: (703) 379-7563 


\title{
NGDRS Phase III — Implementation \\ First Quarter Progress Report
}

\author{
April 1998
}

\section{$\underline{\text { Overview }}$}

All of the hardware is installed and all available databases are loaded into the metadata repository. The final stages of beta testing of GeoTrek and necessary revisions are underway, with a targeted public release of the NGDRS system in April or May 1998.

The Eastern Gulf Region PTTC, Oklahoma Geological Survey, and A2D databases have been converted and loaded into the metadata repository. These are in addition to the four previously installed databases, including the BEG, MMS, PGS, and Fairfield. Data quality improvements, particularly with the MMS and BEG data is continuing, including making the data more intuitive for the typical user.

The beta-testing process has resulted in a number of action items that have been reviewed and addressed. Most of these issues have been resolved, and the remaining issues will be resolved early in the second quarter of 1998, leading to the public launch of the NGDRS metadata repository.

Installation of GeoTrek at the BEG, in an effort to bring their core holdings into the NDGRS, was completed in December. A review was held concerning the experiences of the BEG with GeoTrek during January. The feedback was largely positive, with only a couple technical details to address. A number of companies have also expressed interest and/or are evaluating PetroTrek, the commercial version of GeoTrek. Thus far, most of those companies, including PGS and Fairfield, which have licensed PetroTrek have simultaneously joined the NGDRS as well.

Several data transfer efforts are underway. Vastar has committed to the transfer of 2D Appalachian seismic lines to the NDGRS clearinghouse. Receiving repositories have been identified and the final preparations are being made for transfer to these public repositories. Additionally, discussions continue with the Stapleton Development Corporation concerning the transfer of facilities in Denver for use as a central core repository.

\section{Program Activities Summary}

\subsection{NGDRS Steering Committee Meetings}

Two project review meetings were held in Houston, one on January 22 and the second on February 22-23. These meetings focused on identifying and addressing issues required before the public launch of the metadata repository. 
The January 22 meeting included a review of the beta testing and the development/staging of additional features and databases. As a result of this meeting, a number of issues were identified which are being addressed before the public launch of the metadata repository.

- Improving the memory efficiency of the GeoTrek browser, especially with respect to expansion of the number and depth of the available databases.

- Completing user documentation.

- Finalizing the data advertising and ordering process through the NGDRS.

- Continuing improvement of the user interface in response to suggestions from the beta-testers.

- Partitioning the front-end web material between technical and business issues.

- Formatting the web materials to "look and feel" like the main AGI web site.

A two-day project review meeting was held in Houston on February 22-23. The current system, including the front-end web pages, was demonstrated. Five major issues were identified during the course of the meeting:

- Completion of the front-end web pages and documentation

- Completion of data order procedures for the commercial data providers (Fairfield, PGS, and A2D).

- Completion of the installation of the Oklahoma Geological Survey data.

- Identifying targeted efforts for the next 4 to 6 months, including transfer of Appalachian 2-D seismic tapes, completion of a deal at Stapleton for a central core repository, and the addition of 3 to 4 data sets for the metadata catalog.

\section{Establishing the Clearinghouse}

\subsection{Project status}

The ongoing component projects for the NGDRS and their status:

\begin{tabular}{|l|l|c|}
\hline \multicolumn{1}{|c|}{ Project Name } & \multicolumn{1}{c|}{ Project Type } & Status \\
\hline Houston Core Facility Project & Transfer of Core and Cuttings & Underway \\
\hline Well Log Data Tape Conversion Project & Transfer of Digital Data & Not defined \\
\hline Seismic Data Tape Conversion Project & Transfer of Digital Data & Underway \\
\hline BEG Project & Electronic Database Transfer & Underway \\
\hline PGS Project & Electronic Database Transfer & Completed \\
\hline Kansas Geological Survey Project & Electronic Database Transfer & Delayed \\
\hline Mobil Seismic Sales Project & Electronic Database Transfer & Not defined \\
\hline Metadata Repository Infrastructure & Creation of the Metadata Repository & Completed \\
\hline Metadata Repository Utilization & Utilization and Operations of the Metadata Repository & Underway \\
\hline Mineral Management Services (MMS) & Electronic Database Transfer & Completed \\
\hline Oklahoma Geological Survey (OGS) & Electronic Database Transfer & Completed \\
\hline Eastern Gulf Region PTTC & Electronic Database Transfer & Completed \\
\hline
\end{tabular}




\subsection{BEG - Conversion and Installation}

A review of the Bureau of Economic Geology (BEG) staff experiences using the GeoTrek system installed in December 1997 was performed. The BEG has installed GeoTrek on a server at their facility for statewide access to metadata on their holdings. The Information Store converted and installed their core inventory database for browsing via GeoTrek. As part of the testing process, no tutorial or training sessions were provided to the BEG staff. This was considered a key test of the intuitiveness of the GeoTrek system.

The feedback focused largely on technical hardware and software issues. In general, the databases system worked as expected. However, the BEG is still dominantly a Macintosh-based organization, and the Macintosh Java virtual machine implementation is neither robust nor stable enough to run the GeoTrek browser consistently. However, access via PC's and Unix boxes worked as expected. The BEG is currently evaluating their desktop computing environment and are considering moving to PCs. Meanwhile, C. Keane and A. Eloy agreed to examine options to improve Macintosh-based performance, in particular, use of Sun's HotJava browser.

The BEG is planning to migrate from its current VAX/Ingres database to a Sun/Oracle combination in August 1998. At that point, GeoTrek will be reinstalled on the new system. Once the new system is in place and the tutorials completely written for GeoTrek, staff members at the BEG will receive formal training on using the system.

Additionally, the BEG has solicited a proposal to AGI to develop a core inventory control application to work hand-in-hand with GeoTrek. AGI then will be able to market the core inventory management system together with GeoTrek in an effort to increase participation by core repositories across the country.

The BEG has also requested funding to complete the geocoding of all well locations in Texas with latitude/longitude. Currently, wells within each county are not uniquely locatable. Therefore, in GeoTrek, all wells are shown at the geographic center of their county. The geocoding will provide a latitude/longitude for each well.

An additional database being considered for use in the BEG installation of GeoTrek is a geographically indexed version of the BEG publications catalog. Most of the BEG's publications are geographically oriented and can be fixed to a location or region. This would allow users to geographically browse an area and see what publications are available.

\subsection{Oklahoma Geological Survey - Conversion and Installation}

The Oklahoma Geological Survey core data has been successfully converted and installed on the NGDRS metadata catalog. The TRS2LL software initially believed to handle the conversion between T/R/S to latitude/longitude did not handle Oklahoma. However, Michael Schmidt (Deputy Director of Oil and Gas Conversation Division, Oklahoma Corporation Commission) indicated that a new service was being provided by the University of Oklahoma called "Spatial 
Calculator." This service was used, for a fee, to calculate the latitude and longitude based on the legal descriptions provided in the data.

\subsection{Alabama - Eastern Gulf PTTC}

The well data provided by Ernie Mancini of the Eastern Gulf PTTC has been integrated into the NGDRS metadata repository. As the data was originally in latitude/longitude, it was easily integrated into the system. Approximately 50 records were deleted during quality control caused by repeated or corrupted data.

\subsection{A2D - Conversion and Installation}

Contact with A2D, a Houston area (Humble) provider of digital well logs through the web, has resulted in a firm commitment on their part to join the NGDRS through September 1998. After initial telephone and e-mail contacts with Dave Kotowych, a meeting was held at the offices of The Information Store involving G. Breed and O. Teoh to discuss the business terms and technical requirements. During January, the Information Store worked with Ray Kivimaki, A2D's technical consultant, to discuss the data elements they wish to display and procedures for data installation and refreshing their well log dataset. The A2D data was successfully loaded during February. The initial datasets cover the Gulf of Mexico - both state waters and continental shelf. Procedures for ordering were developed and are being reviewed and tested by A2D staff.

\subsection{MMS}

The loading and testing of the MMS data is now complete. Improving the intuitiveness of the data has begun, with renaming of some of the coded fields as well as default hiding of extraneous columns. The modified MMS database is currently installed in the beta-testing environment.

\subsection{Contribution of Seismic Reflection Data}

Vastar has agreed to contribute over 4000 digital seismic reflection field tapes to the NGDRS. The collection represents some 700 seismic lines extending along the Appalachian Thrust Belt from Southern New York State to Northern Alabama. The 9-track seismic tapes will be transcribed to new high-density tape media prior to transfer to the NGDRS. We are currently soliciting bids for the tape transcription and finalizing a letter agreement with Vastar to facilitate the transfer.

\subsection{Establishing a central core repository}

Based on our studies, we estimate that between 4 and 5 million boxes of cores and cuttings are currently being held in private corporate repositories. The majority of these holdings are available for transfer to public repositories; however, most public repositories are already near capacity. Accommodating such a major transfer of data from the private to the public sector requires identification of substantial new repository space. 
AGI has initiated discussions with the Stapleton Development Corporation to determine if they are interested in donating a former hanger to the NGDRS to serve as a core/cutting research repository. We met with Richard Anderson, CEO/President of Stapleton Development Corporation in Denver on March 16 to review plans for the NGDRS. A letter of intent is presently being prepared to provide a basis for future discussions related to the transfer of the Stapleton properties.

\section{Utilizing the metadata repository}

\subsection{Metadata Catalog Steering Committee}

The committee headed by Robert Merrill (Spirit Energy) and made up of Madelyn Bell (Mobil), John Deery (Amoco), Jacob Loga (PGS), and Jan F. van Sant (AGI) started their activities. The committee's first meeting was held on January 23. A. Eloy provided an update on the NGDRS and other related subjects. The committee expressed strong interest in working with the BEG to get their data sets in order with latitude/longitude and to work at attracting additional data vendors to joining the NGDRS.

\subsection{Web pages}

The front-end web pages for the NGDRS metadata catalog are in a final edit phase. These web pages will provide the first exposure for users to the NGDRS. Two sets of materials are being put onto the web site. First, business-issue related materials are presented in their own section. This includes such things as project information, history of the NGDRS, and a list of frequently asked questions with answers concerning joining and accessing the NGDRS. The other part of these pages relates to technical issues of the GeoTrek browser. This includes information on system requirements, troubleshooting tips, contact points for assistance, and frequently asked questions.

\subsection{Software}

The GeoTrek server software is currently stable and has been deployed in production environments. The browser software is also very stable, especially on Windows 95, Windows NT 4.0, Solaris 2.4, and Linux 2.0.27. A couple user interface intuitiveness issues remain, which are being addressed through the beta-testing process. Additionally, improved memory management schemes on the client side are being investigated, as it is expected that client memory may become an issue as users explore larger and more geographically diverse datasets.

\subsection{Testing}

Beta-testing has been underway since late 1997. A wide range of users, both in discipline interest and computer skill levels, has been enlisted to test the NGDRS metadata catalog system. The beta testers are:

\begin{tabular}{|l|l|}
\hline Person & Organization \\
\hline
\end{tabular}




\begin{tabular}{|l|l|}
\hline Edie Allison & DOE, Washington, DC \\
\hline Madelyn Bell & Mobil, Houston \\
\hline Mary Blount & MMS, New Orleans \\
\hline Todd M Boyd & NASA Maryland \\
\hline Ronald Brignac & MMS, New Orleans \\
\hline George Dellagiarino & MMS, Virginia \\
\hline John Deery & Amoco, Houston \\
\hline Shawn Devlin & Viking Resources-Kansas \\
\hline Eric Hatleberg & POSC, Houston \\
\hline Allen Hittelman & NOAA, Denver \\
\hline Christopher Keane & AGI, Virginia \\
\hline Shinji Kanai & JNOC, Japan \\
\hline Ben Lin & Unocal, Houston \\
\hline Jacob Loga & PGS, Houston \\
\hline Jenny Meader & POSC, Houston \\
\hline Robert K. Merrill & Spirit Energy, Houston \\
\hline Chandra Nautiyal & DOE, Tulsa \\
\hline Esteban Quijano & SECTEC, Mexico \\
\hline Gary Stone & Five States Energy \\
\hline Sherilyn Williams-Stroud & USGS, Denver \\
\hline
\end{tabular}

\subsection{Interaction with NASA’s Global Change Master Directory}

In January, a meeting was held at the operational center for NASA's Global Change Master Directory in Greenbelt, Maryland. The GCMD is a NASA effort to provide a first-tier metadata catalog of available datasets related to earth science issues. The GCMD is part of the National Spatial Data Infrastructure, and provides an important service in assisting users to identify appropriate databases based on subject keywords and geographic location.

A dialogue was opened with the GCMD about how the NGDRS and GCMD could cooperate, in a mutually beneficial manner and ensure that no duplication of effort was being made. From a mission, data source, and user level, it is clear that the NGDRS and GCMD are complimentary to each other and do not represent a duplication of effort. Additionally, Lola Olsen, project director for the GCMD, volunteered to have her staff create the Database Information Files (DIF) for the NGDRS component databases. A preliminary DIF has been written for the MMS well database as an example. These DIF's will be incorporated into the GCMD system, helping publicize the NGDRS's existence. Additionally, the NGDRS inclusion into the GCMD represents the first databases of analog resources to be included, opening and entirely new avenue for expansion of the GCMD.

It was agreed that open communications should continue, and that an overall efficiency in cataloging the available analog geoscience data is best handled by the NGDRS. The GCMD will continue to write appropriate DIFs for NGDRS-cataloged databases as they become available, 
providing subject and keyword access to the repository databases to the wider geoscience community. 